\title{
0 papel da educação na humanização
}

\author{
Wilson Buzinaro
}

Professor de História e Chefe do Departamento de Ciências Humanas e História do CESUP. Mestrando do Programa de Mestrado em Educação da UCDB.

\section{Enfoques introdutórios}

Educação é um tema muito falado, comentado hoje em dia. Seria muito difícil citar as várias correntes e teorias educacionais existentes analisando as suas propostas inovadoras. Sem dúvida, cada uma tem o seu lado positivo e contribui no sentido de buscar uma melhor alternativa para que o processo ensino-aprendizagem possa ser mais acessível aos alunos. O presente trabaIho não tem o objetivo de ser mais uma teoria, mas é uma inquietação, uma experiência profissional deste educador, que há muito se detém sobre os problemas da educação brasileira e procura, na sua prática de vida, buscar soluçōes para os mesmos.

O tema Educação e Humanização que neste trabalho é exposto, procura resgatar o ser humano como sujeito da sua história, uma vez que o mesmo está sendo objeto passivo de determinaçōes sociais. É uma tentativa de se mostrar que o homem precisa antes de tudo resgatar a sua humanidade, isto é, resgatar os seus valores humanos, para que junto com o conhecimento livresco, necessário, possa se colocar na po- sição de agente transformador da realidade em que vive. Da mesma forma, procura questionar a ação das entidades, instituiçōes e pessoas que trabalham na formação dos nossos jovens, ponderando alguns pontos vivenciados por este educador.

Portanto, não é o presente trabalho um receituário, mas sim um sinal de alerta a todos os educadores compromissados com a mudança e transformação da sociedade em que vivem e onde desenvolvem a sua ação formadora-pedagógica.

Analisando a história, percebe-se desde o início que a busca do ainda não conhecido foi o grande desafio do ser humano. Descobrir e desvendar a natureza, os fatos, os fenômenos sempre foi a meta propulsora que permitiu a evolução do conhecimento humano. A fase primitiva da espécie humana se caracterizou pelas explicaçōes religiosas e mitológicas dos fenômenos, não havendo espaços para explicaçōes naturais.

O direcionamento das atitudes do homem é determinado pelas suas crenças não questionadas pelo grupo, pois o primitivo é grupo e não sujeito da sua histó- 
ria. É grupo, e não tem consciência de ser membro do grupo. O processo de educação é baseado na transmissāo de tradições e costumes de geração para geração de acordo com os interesses individuais do grupo, sem questionamento e consciência individual, caracterizado assim como educação coletiva.

Com a chegada da filosofia, Civilização Grega, nasceu a preocupação de buscar explicaçōes racionais para a realidade, superando o estágio das explicaçōes mitológicas. A filosofia despertou o ser humano a buscar a sua condição de pensante e sujeito da história diante da realidade em que vivia. Neste estágio ocorre a diferenciação da educação de um grupo para outro. O exemplo típico dessa diferenciação está presente em Esparta (militarismo, valor no físico) e Atenas (democracia, artes...).

Mesmo procurando a sua individualidade, o homem não consegue, e nem seria possível, afastar-se das determinaçōes do grupo, da sociedade. As suas atitudes e decisões não são individuais e sim sociais.

O Renascimento procurou abrir horizontes e despertar o homem parado e estagnado da Idade Média. A educação teocêntrica medieval é rebatida com a proposta antropocêntrica renascentista que procura valorizar o natural, o humano. A visão sobrenatural dos fatos cede lugar à visão natural.

Como a passagem para o capitalismo, o homem é educado para produzir. A visão do útil predomina, sobre os valores do ser humano. Em nome da produção, fica esquecido como pessoa cheia de potencia- lidade. A educação passou a funcionar como mecanismo de apoio à melhoria da qualidade desta produção.

O ser humano, hoje, encontra-se exatamente dentro desta visão capitalista. E é dentro desta realidade que ele precisa ser educado. Não há como buscar soluçōes e alternativas na melhoria do processo de ensino-aprendizagem fora deste contexto.

Que papel a educação deve, então, exercer tendo em vista o processo de humanização? Que tipo de educação precisa este homem para superar a visão pura e simples de máquina e objeto proposta pelo capitalismo? Como se encontra hoje a educação brasileira e até que ponto é humanizadora?

\section{Característica da educação brasileira}

Alguns pontos devem ser considerados quando se analisa a educação brasileira. Existe uma exagerada ênfase à reprodução pura do conhecimento, através da qual é valorizada a acumulação e memorização de conceitos e informaçōes. Não há preocupação com o raciocínio, uma vez que o aluno não é chamado a pensar, a buscar o novo, o que não está determinado. Esta atitude não permite o desenvolvimento de atividades ligadas à fantasia, à imaginação, à pesquisa. Promove-se, portanto, apenas algumas facetas do potencial existente em cada indivíduo, contribuindo assim para uma formação parcial e desequilibrada, inibindo e dificultando a manifestação de outras potencialidades do aluno. 
Repetir o que já está pronto e conhecido não é papel da educação. No entanto, o que se vê na educação brasileira é ausência de mecanismos que desenvolvam o lado criador, inovador, imaginativo, tão necessário para o crescimento integral do ser humano.

Como este tipo de educação prepara a geração do século XXI? Que grau de capacidade e raciocínio terá o aluno que vivencia esta educação hoje voltada para o passado, para o domínio dos fatos conhecidos? Que tipo de espaço terá, neste aluno, a arte, a cultura e a espiritualidade? São indagaçōes pertinentes e que devem incomodar as pessoas que trabalham na educação.

Dentro desta mesma linha está o ensino universitário. A universidade brasileira há muito, se é que foi, deixou de ser viveiro e transformou-se num marasmo de idéias e intençōes. Não há espaço para os iniciantes. A busca do novo fica limitada a uma pequena parcela de pessoas, em função da garantia de status para a elite.

Volta-se à reprodução do conhecimento, pois não havendo espaço para a busca do novo, procura-se "engolir" o que é conhecido e determinado.

Como adquirir uma educação humanizadora diante deste quadro presente na educação brasileira? Qual o caminho a percorrer quando se tem por objetivo a valorização do sujeito, da pessoa? É um caminho que se faz através de conscientização e trabalho individual, ou necessariamente passa pelo coletivo?

\section{Educação: uma busca de huma- nização junto com os outros}

O homem é um ser social e só se realiza vivendo em sociedade. Cada um está diante da situação total que o envolve, os outros e as condiçōes em que vivemos todos. É muito difícil buscar a realização pessoal isolando-se da realidade existente. A sociedade determina padrōes econômicos, culturais, artísticos, políticos com os quais se convive e interfere no posicionamento individual das pessoas. Mas é nesta sociedade, específica, determinada e real, que o indivíduo deve buscar a sua realização.

Diante disso, não há como existir educação humanizadora sem que esta ultrapasse o campo do "eu", a esfera do individual. Educar é o ato intencional de criar cultura e este ato exige a possibilidade de poder dialogar com os outros. A educação se realiza através do diálogo, da troca de experiência entre os envolvidos. Não há educação humanizadora quando existe o que sabe e o que nada sabe. Ignorar a experiência do educador é condená-lo a ser um mero e simples reprodutor do que já existe e é conhecido.

Através deste diálogo, o ser humano procura encontrar o seu espaço, a sua verdade pessoal dentro da realidade em que vive. Esta verdade pessoal não é fruto do puro individualismo, mas nasce da interação com as outras pessoas. A partir do momento em que o indivíduo se conscientiza desta condição social para a realização pessoal, ele procura também exprimir e buscar a sua verdade social e humana. 
Pode-se afirmar, então, que a realidade pessoal só é possível se estiver acompanhada da realização social e humana. Para isso, a educação é o meio mais eficaz para formar pessoas capazes de atuar profissionalmente numa realidade.

Não há dúvidas de que a educação é o melhor caminho para se promover a realização e humanização pessoal e social das pessoas. E esta educação deve estar inserida numa realidade, na qual as pessoas vivem e se desenvolvem. Será que se pode afirmar que a nossa educação de fato está voltada para as necessidades que o processo humanizador exige?

Em muitos momentos, temos a impressāo de que nosso processo educacional se reduz à própria dicotomia de cada dia: não vai além disso. Não é compatível com a dimensão humana de educação, pois o que vemos hoje é constante monólogo de professores ou de livros, obrigando os seus educandos a serem e terem apenas a capacidade de reproduzir. Os conteúdos ministrados não são assimilados e não há processo de superação, provocando assim a escravidão e domesticação do indivíduo, deixando de lado a criatividade e os valores individuais que podem e devem ser manifestados em qualquer processo educacional.

Como, então, entender a educação como uma busca de humanização que se realiza junto com os outros, quando é negada a participação de uma das partes no processo educativo? Educar é prepará-la para se inserir num processo (que se modifica a cada momento) ou é procurar adaptá- la à sociedade, que a envolve e determina, negando a sua condição de ser pensante e sujeito da história? Mesmo necessitando do outro para se realizar, o indivíduo não se pode negar como pessoa. As características individuais é que possibilitarão a formação e o crescimento do todo. Cada pessoa tem algo a oferecer, por menor que aparentemente seja este "algo", de grande valia para o crescimento dos demais.

A educação deve transformar o homem mais num ser que busca com os outros que num homem que "sabe" "(caricaturando os informadíssimos acadêmicos que lêem, sabem tudo, falam bonito e complicado e não fazem nada com sua sabedoria)".

É papel da educação formar o indivíduo com capacidade de repensar o pensado, ou seja, com capacidade de refletir e fazer constantemente a sua atuação. Além disso a educação deve possibilitar o desenvolvimento dos valores individuais sempre vinculados aos sociais, pois não há educação humanizadora apenas individual. É preciso que ela seja voltada para o contexto social, a fim de que possa propor alternativas de mudanças em prol da humanização das pessoas que podem ou precisam ser transformadas. Isso não significa que se deve determinar padrões educacionais. Pelo contrário, aqui se defende a necessidade de respeitar a individualidade de cada pessoa, de acordo com suas características, buscar a sua realização que passa, necessariamente, pela convivência e aproximação com o outro. 


\section{Os conceitos de pessoa e processo educacional}

É necessário que se busque uma educação que capacite, a cada instante, a avaliação da experiência, tornando possível repensá-la continuamente. Para que isto seja possível a educação não pode estar voltada para a simples recepção de informaçōes, mas sim para a busca do novo. 0 processo educacional estará de acordo com a concepção de pessoa que se tem. Havendo o conceito de que a pessoa não inova e não produz, a concepção de educação será domesticadora. Não haverá objetivo de transformar a realidade, mas de se adaptar a ela. Se o conceito de pessoa estiver dentro da visão de que o homem é um ser que a transforma, a educação estará voltada para responder aos desafios que a realidade traz. A pessoa não pode, nesta perspectiva, reduzir-se a mero espectador da realidade, ou a mero resultado da ação condutora de outros homens que o tornam um objeto. Um sujeito que opera e transforma o mundo será a característica fundamental desse conceito de pessoa.

O homem é um sujeito que busca com os outros. Ninguém deve e consegue buscar sozinho, pois toda busca isolada sempre é movida por interesses pessoais e é, necessariamente contra os demais. Não se admite aqui 0 assistencialismo. Ninguém deve ficar esperando o resultado do outro. O processo de humanização é junto com outro.

Nas relaçōes do homem com os demais e com a natureza tal como se apresenta, juntos, encontram o ponto de parti- da para a transformação da realidade. 0 aqui e agora é o ponto de partida de superação da situação atual. Portanto, quanto mais se conhece a realidade em que se vive, mais profunda será a transformação da mesma. Sempre o homem procura "ser mais". A harmonia com a natureza com os demais, possibilita, ao homem, a sua realização completa, a busca da sua humanização. A desumanização obriga este homem a se posicionar como um ser passivo de pura adaptação e não de transformação do mundo. Que sentido teria o ser humano se ele se colocasse dentro dessa visão?

A existência humana é uma opção permanente entre a humanização ou desumanização. Respeitar, portanto, as condiçōes específicas de cada pessoa é condição primeira de todo o processo educacional, pois este deve estar em função das especificidades e individualidades do educando. É claro que aqui se trata da especificidade positiva, ou seja, aquilo que é individual, mas que possibilita o crescimento da pessoa e do coletivo e não a acomodação perante uma situação com a justificativa de que se está respeitando a pessoa como ela é, pois isso é extremamente prejudicial à formação do indivíduo, uma vez que muitas atitudes e características pessoais devem estar continuamente em processo de mudança e melhoria.

\section{Educar é humanizar ou domesticar?}

A educação só é verdadeiramente humanizadora se houver um esforço no sentido de capacitar o homem a conhecer 
e analisar criticamente a realidade, possibilitando-lhe transformá-la e não apenas adaptá-la. Se a educação enfatiza os mitos e encaminha o homem a uma adaptação à realidade ela é dasumanizadora.

Neste contexto, aparecem duas concepçōes de educação: uma que humaniza e outra que domestica a pessoa.

A concepção domesticadora também é conhecida como educação "bancária", pois faz do processo educativo um ato permanente de depositar conteúdos levando a uma passividade do educando.

Esta concepção não supera a dicotomia educador-educando e isso traz algumas consideraçōes relevantes: o educador se apresenta como aquele que educa; o educando, o que é educado. O educador é quem disciplina, fala, prescreve, escolhe o conteúdo e programas e se coloca como dono do saber; o educando é o disciplinado, é o que escuta, segue a prescrição, reproduz os conteúdos, sendo colocado na situação de quem não sabe.

Segundo essa concepção, o educando é como se fosse um "reservatório" no qual o educador vai fazendo seus depósitos. Um "reservatório" que vai se enchendo de "conhecimentos" como se o conhecimento fosse o resultado de um ato passivo de receber doaçōes. Nada resta aos educandos senão receberem os "depósitos", arquivá-los e memorizá-los para depois repeti-los.

A preocupação fundamental dessa concepção é mistificar a realidade e evitar a inquietação. É evitar a desocultação da realidade a fim de adaptar o homem. Não se propōe fazer o homem compreender criticamente a realidade e inserir-se nela para transformá-la.

A concepção humanizadora de educação jamais separa o homem do mundo. Afirma que saber é arriscar e criar, que não há saber sem busca inquieta, sem a aventura do risco de criar.

É sua tarefa desmitificar a realidade e promover um trabalho problematizador. Não adapta o homem mas o faz um transformador do mundo. Recusa os "depósitos", a mera dissertação ou narração da realidade. Seu trabalho problematizador busca superar a dicotomia educador-educando.

Enquanto que para a concepção "bancária" o que importa é depositar informes, sem nenhuma preocupação com o despertar de reflexão crítica, para a concepção problematizadora o fundamental é o que se deve cada vez mais explicitar. A concepção problematizadora, ao desafiar os educandos através de situaçōes existenciais concretas se constitui em verdadeiro trabalho humano. Uma educação depende do diálogo entre os homens. Não há educação verdadeira dissociada da reflexão e da ação sobre o mundo.

Não há como admitir, na atual realidade em que se vive, uma educação que não seja humanizadora; que não procure oportunizar aos educandos a buscarem os desafios; que não esteja voltada para a valorização das qualidades e potencialidades da pessoa; que não proponha alternativas de mudanças da real situação na qual os educandos estão inseridos; que não vá além da pura e simples reprodução do que 
já é conhecido, que não promova a busca do não conhecido; que não veja o educando como ser compartilhador do processo ensino-aprendizagem.

\section{Considerações finais}

O processo da educação se realiza dentro de uma dinâmica, proporcionando uma constante dialética. A mente humana é "insaciável" e sempre abre e cria novos horizontes, desafiando os seus limites. Ao longo da história, porém, o que se constata é que a educação sempre esteve a serviço da elite, reproduzindo o conhecimento. Como é possível, dentro desta realidade histórica, pensar em educação humanizadora sem antes pensar em mudar a ordem social vigente? O caminho, necessariamente, é a busca da educação que problematiza e conscientiza, deixando de lado a educação "bancária", pronta, acabada.

É, pois, necessário abrir horizontes e analisar os desafios quando se pensa em educação. Não se aceita uma educação apenas para hoje. É imprescindível olhar o amanhã proporcionando, no dia-a-dia, as condiçōes necessárias para enfrentar o futuro. É necessário repensar a educação, não só em nível de conteúdo, mas também no âmbito dos traços de personalidade a serem reforçados e cultivados pelo sistema. A visão do "aluno ideal" precisa ser revista. Não é a obediência, a passividade e o conformismo que devem ocupar o lugar de destaque na educação, mas é preciso inserir a coragem, o compromisso, a dedicação, o entusiasmo, a criatividade, a busca e a autoconfiança. Só assim se pode partir para a busca de novas respostas e soluçōes, superando a reprodução do conhecimento.

Espera-se, portanto, que a educação abra espaços para o desenvolvimento não apenas do tradicional, mas também para o novo; para a reprodução e para a criação; que possibilite o desabrochar das características incubadas em cada aluno, favorecendo a expansão do talento e das potencialidades individuais.

\section{Bibliografia}

BUZZI, Arcângelo R. Introdução ao pensar. Rio de Janeiro: Vozes, 1988.

COTRIM, G. História e filosofia da educação. São Paulo: Saraiva, 1991.

FREIRE, P. Pedagogia do oprimido. Rio de Janeiro: Paz e Terra, 1987. . Educação como prática de liberdade. Rio de Janeiro: Paz e Terra, 1967. 
